Revista Iberoamericana. Vol. LXVII, Núms. 194-195, Enero-Junio 2001, 69-78

\title{
LOS LÍMITES DE LA TRANSGRESIÓN: LA VIRILIZACIÓN DE LA MUJER Y LA FEMINIZACIÓN DEL POETA EN JOSÉ MARTÍ
}

POR

JoRge Luis CAMACHO

Arkansas Tech University

En el siguiente ensayo me interesa resaltar la construcción del otro femenino en el panorama de la modernidad sociohistórica y literaria. Entraré a analizar el doble discurso de la masculinización de la mujer y la feminización de la figura del poeta en Martí, discurso que vincula al vate con lo pasivo, lo bello y frágil, atributos todos, tradicionalmente asociados a la mujer, mientras critica en la mujer lo que entiende como un exceso de virilidad. Me interesa demostrar cómo en Martí se trasluce una ansiedad por una belleza mítica, y ambigua, fundada en el ideal del andrógino de la que se sirve en muchos casos para describir a los "seres superiores" que se propone imitar.

En el siglo XIX, con la incorporación de la mujer en gran escala al mercado de producción entran en crisis las divisiones tanto de trabajo como simbólicas que habían caracterizado hasta entonces las relaciones sexuales. La mujer se convierte en productora de bienes de consumo; consumidora, ella misma, de un gran bazar de bisuterías, vestidos y adornos en la cultura de las grandes tiendas, y se convierte en un producto masificado en la industria sexual. Surgen además en esta época el movimiento feminista, los grupos a favor del sufragio universal, y la incorporación de la mujer cada vez en mayor número a las instituciones educacionales. Como afirma Buci-Glucksmann este proceso representó una doble pérdida para la mujer: la de sus cualidades "naturales” a las que tradicionalmente estaba asociada (lo femenino, su papel de madre, su rol dependiente, pasivo), y la de su “aura” poética, su belleza sublimada por una larga tradición desde el Renacimiento (222).

Entre 1880 y 1882, Martí critica en diversas crónicas estos cambios. Sismógrafo de la sociedad norteamericana de la época, el cubano constata con asombro, lo que denomina una progresiva virilización de la mujer en la sociedad neoyorkina, cuyas nuevas costumbres en medio del turbión de la vida moderna las “despojaba” de "la antigua gracia,” que convenía en las mujeres. Escribiendo originalmente en inglés para el periódico The Hour, Martí afirma en un artículo de la serie "Impressions of America (by a very fresh Spaniard)”:

¿Pero por qué han de verse las mujeres tan varoniles? Su rápido andar al subir y bajar las escaleras, en el trajín callejero, el gesto resuelto y bien definido en todos sus actos, su presencia demasiado viril, las despoja de la belleza serena, de la antigua gracia, de la exquisita sensibilidad que conviene a las mujeres en aquellos seres superiores - de los cuales dijo Calderón que eran “un pequeño mundo”. (Obras completas XIX, 116) 
En 1880, fecha en que aparece esta crónica, Martí había acabado de llegar a los Estados Unidos, de ahí que el título de la crónica lo caracterice como un “español recién llegado”. No obstante, las opiniones de Martí son bastante críticas y expresan de forma elocuente el cambio de valores que tiene lugar en la sociedad de la época. Muestra además la inusitada alarma, la molestia casi, del cronista que lee simultáneamente dos culturas: la norteamericana y la española, y que juzga los valores tradicionales sobre los modernos. La agresividad de la mujer norteamericana, su “trajín callejero," su "gesto resuelto y bien definido” son aquí los síntomas inquietantes de una virilidad y una independencia que debe ser exorcizada, devuelta a los márgenes de lo social y tradicionalmente permitido. No es de extrañar entonces que frente a este sujeto, el hablante se muestre indiferente sexualmente, y prefiera, como dice, las mujeres de su país a la mujer norteamericana.

Desde el punto de vista social, la descripción que hace Martí de esta mujer “demasiado varonil” corresponde a la descripción de lo que en los periódicos de Francia, Inglaterra y los Estados Unidos se llamó la femme nouvelle o the New woman. Como sugiere Elaine Showalter "politically, the New Woman was an anarchic figure who threatened to turn upside down and to be on top in a wild carnival of social and sexual misrule" (38). En Francia era a menudo caricaturizada en los periódicos como una cerveline "a dried-up pedant with an oversized head; an androgynous flat-chested garònnet, more like a teenage boy than a woman; or a masculine hommesse" (39). Martí parece hacerse eco nuevamente de estas críticas cuando en su Prólogo al "Poema del Niágara” afirma que en las nuevas condiciones sociohistóricas "Dios anda confuso; [y] la mujer como sacada de quicio y aturdida” (VII, 228). Para este sujeto amenazante y desquiciado sólo quedaría un lugar: la clínica, el ático, la mesa de disección; de ahí la obsesión fin de siècle con la histeria, los órganos reproductivos de la mujer, y las secuelas de la herencia

Juntamente con el proceso de "virilización” del sexo femenino, ocurrió también un proceso inverso de feminización del poeta, reflejo de la intensa movilidad en que se redistribuían los códigos y valores simbólicos en una sociedad altamente industrializada. Este doble proceso es constatable en los poetas simbolistas franceses, en los prerrafaelitas, y en los modernistas hispanoamericanos. Y en efecto, en las representaciones estéticas de Charles Baudelaire, Gustave Moreau, Oscar Wilde, y otros, aparece un cuerpo que se define genéricamente como otro. Tanto en la escritura como en la práctica histórica aparece un espacio absolutamente imaginario que disloca y borra las fronteras de lo opuesto, de lo femenino y lo masculino, de lo arcaico y lo moderno, creando así lo que Christine BuciGlucksmann llama "transgressive utopia” (221). "Brazos fragantes” de Ismaelillo (1882) es un poema idóneo para leer este doble traspaso de valores en la poesía de Martí. El proceso de masculinización de la mujer y la autorrepresentación del poeta como "frágil” y "femenino".

El poema comienza con una imagen metonímica, en que dos brazos rodean el cuello del amante. Al sentir la caricia de estos brazos, el cuerpo del poeta, “como rosa / Besada se abre”. Su cuerpo crece bajo las sensaciones eróticas, "se abre” como una flor. Si aquí el cuerpo aparece metamorfoseado en una planta, "rosa”, sobre la cual vuelan "mariposas inquietas”, la sangre a su vez, lo hará en la "savia” que recorre "las muertas carnes” del poeta, que "lánguido exhálase” en su "propio perfume”. Afirma Martí: 


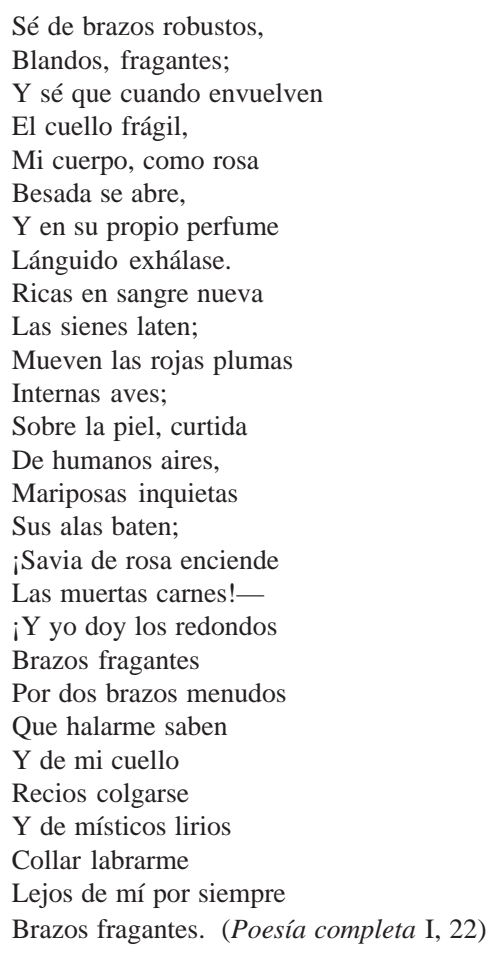

Al final del poema, Martí rechaza los brazos de la mujer por los del hijo. No obstante, quiero argumentar que ese rechazo ya está implícito en el encuentro amoroso descrito al inicio; en el miedo inexplicable del hablante poético a deslizarse hacia el terreno del cuerpo en el poema, lo cual produce una explosión de significantes con el propósito de llenar ese vacío, de cubrir ese cuerpo, rasgo típico a su vez de los juegos barrocos. A partir de la palabra “cuello” y la acción de ser abrazado por la amada, la descripción del cuerpo y la exaltación erótica se borran, se disuelven en imágenes vegetales. Desde ese momento, el cuerpo aparecerá metamorfoseado en una flor y fragmentado: "sangre”, "sienes”, “piel”, “carne”. La claridad del inicio del poema contrasta con esta otra descripción, digamos oscura, del enlace sexual. La representación del cuerpo entrelazado con imágenes bucólicas, evita cualquier satisfacción vicaria ante el acto erótico, evita caer en el erotismo, en lo que él mismo llamó “el falerno meloso” de las melodías sensuales y paganas (VII, 224), pero también liga indisolublemente el mundo animal y el vegetal en el poema. Savia/sangre, cuello/tallo, ambos mundos se relacionan de parte a parte. Uno está en el otro. Ligan el cuerpo con una fuerza vital y primigenia. De esta forma, el cuerpo habla un lenguaje que expresa el ritmo del universo. En él confluyen los “opuestos”, las “corrientes” todas del cosmos. La decisión final de rechazar el erotismo nos dice que lo natural es un espacio que debe ser reprimido en función de lo ético y lo espiritual. Si Martí se identifica a sí mismo 
aquí con una “rosa besada”, el hijo, alter ego del padre, será una “rosilla nueva” en el poema de este título que cierra el libro (I, 47).

La escritura del cuerpo es aquí transgresora por el simple hecho de que Martí invierte la forma tradicional en que éste es representado y crea un espacio completamente utópico donde se integran lo femenino y lo masculino, el mundo vegetal y el cuerpo humano. La mujer adquiere aquí rasgos ambiguos, y ante ella el poeta se autodescribe como frágil y femenino. Además de que no hay nada más femenino que una flor para referirse a un poeta, como el propio Martí hace un poco despectivamente en el Prólogo al "Poema del Niágara". En tal ocasión cuando el cubano habla de la lírica sensual compara los hombres con "hembras débiles” y específicamente, son estos personajes los que luego utilizará cuando se refiera a los cargos de homosexualismo en Whitman. Afirma Martí en un tono colérico: "hembras débiles parecerían ahora los hombres, si se dieran a apurar, coronados de guirnaldas de rosas, en brazos de Alejandro y de Cebetes el falerno meloso que sazonó los festines de Horacio. Por sensual quedó en desuso la lírica pagana” (Obras completas VII, 224).

Aníbal González afirma que en estas líneas Martí se está refiriendo a la literatura decadentista que el cubano veía como “excessively effeminate”, y que por tanto “considered it unsuitable to form the basis for the new American literature he wanted to create" (II, 90). Y en efecto, el temor a la desvirilización de la poesía y del poeta son tópicos recurrentes en Ismaelillo y en el Prólogo al "Poema del Niágara”. Paradójicamente, junto al sensualismo del poema, el hablante poético aparece aquí representado como una “rosa”, mientras la mujer adquiere rasgos ambiguos. Recordemos que la imagen metonímica del principio del poema da paso a una imagen de confluencia de opuestos. Son brazos "robustos/blandos", y son asimismo, seductores y agresivos. En el fragmento antes citado sobre la mujer norteamericana, Martí sugiere que la mujer debe imitar a los “seres superiores” de los cuales dijo Calderón eran “un pequeño mundo”. Paradójicamente, el dramaturgo español dice esto cuando se refiere sólo a los hombres. La comparación aparece en dos lugares de su obra; una de ellas en el auto sacramental No hay más fortuna que Dios, donde Calderón pone en boca de los músicos allí de paso el siguiente comentario: “Alábese la Hermosura / de que si en algún concepto / el Hombre es pequeño mundo,/ la mujer pequeño cielo” (625). Ahora bien, es probable que Martí estuviera pensando en la mujer-varonil del barroco español que tiene su antecedente en el ideal del andrógino, y la mujer de uno y otro género. En Ismaelillo el poeta llama por el nombre de "Rosauras" a las mujeres que están en el baile en una alusión evidente a la obra de Calderón La vida es sueño. Con estas referencias, Martí parece dar a entender que cierta dosis de virilidad era posible y hasta deseada en la mujer, pero que nuevamente, era el exceso de ésta, el hecho de que se vieran "tan varoniles", y “demasiado viril[es]”, lo que le molestaba. Parece pensar que a esto contribuían las nuevas condiciones sociales, a pesar de que en reiteradas ocaciones aboga por la educación de la mujer, y su incorporación al trabajo.

Por otro lado, no debe ignorarse el dato biográfico de que en su etapa adulta "Martí ama a mujeres de carácter íntegro, valeroso y enérgico, aplicando siempre el paradigma de la madre, lo que justifica la identidad caracterológica” según Aníbal Rodríguez, “existente entre Leonor Pérez y Carmen Zayas Bazán”, la madre y la esposa (395). En cuanto a su propia representación en el poema, Martí juega a transgredir la línea de lo socialmente 
permitido para postular un espacio utópico imaginario demasiado femenil. Esto, como sugiere Foucault, crea entonces en el poema espacios de tensión entre lo permitido y lo prohibido, y por eso no basta con que el poeta convoque una escena erótica en donde se intercambian los roles genéricos. Es necesario ahora rechazar esa visión, postulando nuevamente el marco inquebrantable del deber-ser. Si Martí se distancia con la prosa de tales autorrepresentaciones, en su poesía parece acercarse, intentar por un momento, el simulacro de una transgresión.

Una vez dicho esto, habría que enfatizar el matiz provocador que debieron tener estas imágenes, del cual Martí estaba seguramente consciente. Muestra de ello sería que la mayoría de los ejemplares del libro permanecieron inexplicablemente en los cajones del escritor y cada carta con la que enviaba el libro a sus amigos más cercanos era a su vez una disculpa. ¿ ¿No podrían malinterpretar ellos esta autorrepresentación del poeta como flor? ¿No podría parecer demasiado narcisista? Recuérdese que estamos hablando de una sociedad profundamente machista, regida por códigos patriarcales y de una tradición española cuya pudibundez literaria es legendaria. Si a esto sumamos el hecho de que quien escribe aspiraba a dirigir la lucha por la independencia de su patria, hay razones poderosas para comprender por qué esa renuncia al sexo, en cualquiera de sus formas, en el poema.

De nuevo, es sintomático que en este poema el hablante nunca se identifique ni identifique al otro como masculino o femenino, que nunca utilice pronombres como "él” o "ella”. Sabemos que quien escribe es Martí, pero ha sido esta ambigüedad de roles en el poema lo que ha provocado, a mi parecer, lecturas contradictorias.

En "La doble 'otredad' realizativa en Ismaelillo", Angel Esteban afirma que los brazos robustos pertenecían al poeta y por eso llega a la conclusión de que "el poeta sería capaz de dar sus brazos robustos, hartos de trabajar, por aquellos en los que hay una fuerza interior asombrosa, misteriosa ' $\mathrm{i} Y$ yo doy los redondos / Brazos fragantes, / Por dos brazos menudos / Que halarme saben”” (188). Sin embargo, Díaz Quiñones entendió que los "brazos fragantes", "robustos" eran los de la mujer y que este poema materializaba las "guerras del alma”, el rechazo del erotismo por el ascetismo del guerrero, los reclamos de la patria y la nación. Ambas interpretaciones se publicaron al mismo tiempo, de ahí que los autores no hayan podido darse cuenta de tal contradicción. Y es que tanto la representación de la “mujer” como la del "hombre” aquí son partícipes de una ambigüedad genérica que recorre toda la literatura y la pintura del siglo xix. La voz lírica es en este poema una voz andrógina.

Fue Alejo Carpentier quien en su ensayo, “Martí y Francia”, llamaría la atención sobre la perspicacia de ciertas representaciones eróticas que señala Martí en Gustave Moreau. En tal ocasión, Carpentier haría un breve paralelo entre las opiniones del cubano y las de Marcel Proust a propósito de la indeterminación de géneros en las figuras del pintor decadentista. Decía Carpentier:

Como habrá de hacerlo Proust, señalaba la ambigüedad, entre masculina y femenina ambigüedad totalizadora, hallada en el brote primero de los mitos: Agraxas de la simbología alquímica — de ciertas figuras de Moreau, al decirnos que su Galatea 'aun poseyendo la más suave forma femenina, no es una mujer’. (513)

Martí está describiendo un cuadro del francés donde Galatea aparece observada desde lo alto por el Cíclope. La ninfa extiende su mano provocadoramente. Creemos que la misma 
ambigüedad que Martí y Proust encuentran en los cuadros de Moreau, se halla en los protagonistas de "Brazos fragantes", y otros poemas del cubano, y que esta atracción/ rechazo por sexualidades ambiguas está dentro del gusto decadentista y fin de siglo. Podemos representarnos entonces la relación sexual de este poema a través de la oposición por negaciones que hacían Freud y Lacan: "Yo (hombre/mujer) amo/odio a ti (mujer/ hombre)" (Écrits 188).

Martí se refiere a la unión de características genéricas distintas en la crónica sobre Whitman, a quien defiende de los ataques de quienes creían detectar, en el regodeo de ciertas imágenes de su famoso libro, las celebraciones de un homosexual. Comentando un poema de Walt Whitman sobre una madre y su hijo, Martí afirma que el norteamericano:

Prevé que, así como ya se juntan en grado extremo la virilidad y la ternura en los hombres de genio superior, en la paz deleitosa en que descansará la vida han de juntarse con solemnidad y júbilo digno del Universo, las dos energías que han necesitado dividirse [la madre y la del hijo] para continuar la faena de la creación. [énfasis nuestro] (XIII, 138)

El poema de Walt Whitman, que Martí transcribe en su crónica, es extraordinariamente breve para su modo de escribir y, sin embargo, Martí encuentra en él un sentido trascendente, escatológico, que se manifiesta en una concepción del universo unívoco. De nuevo, como en el caso de Calderón, Martí hablando ahora a través del poeta norteamericano nos dice que quienes reúnen características opuestas "en grado extremo" son seres de "genio superior". Martí parece hacerse eco aquí de la concepción neoplatónica del ser que en un pasado conformaba la unidad paradisíaca, era parte del gran todo y que tras la caída, da paso a la división y el exilio. Este conflicto lo anima en el trayecto y la búsqueda original, que sólo en una vida futura, en la reunión con el Uno-todo, “en la paz deleitosa en que descansará la vida” estos fragmentos desunidos y hostiles encontrarían una refundición. De ahí, la angustia romántica y modernista con la antítesis, la ironía y los lados opuestos de las “correspondencias”. El ser romántico se sabe escindido, fragmentado; su lucha agónica estará en reconstruir esos fragmentos.

Más importante aún, con esto Martí parece recordarle a sus lectores que no hay por qué confundir homosexualismo con androginia, el mito con la realidad. Aunque Martí no utiliza la palabra "homosexual”, que sí conocía, es evidente que trata de “imbéciles” a quienes creen ver en la forma de describir el poeta norteamericano "el amor de los amigos", "el retorno a aquellas viles ansias de Virgilio por Cebetes y de Horacio por Giges y Licisco" (XIII, 137). Martí ni siquiera enuncia el topos de la "pose” o la "simulación” para descalificar estas opiniones. Su negación en tal sentido es rotunda. Y para explicarlo acomoda la voz asexuada del poeta dentro del mito del hermafrodita. Por eso Martí compara a Whitman nada menos que con Safo, cuando asegura que "Con el fuego de Safo ama este hombre al mundo” (XIII, 137). De hecho, en el comentario que citamos anteriormente sobre Whitman, Martí está repitiendo, casi textualmente, lo mismo que había dicho Emerson, fuente indiscutible de la filosofía de ambos, en su libro English Traits sobre los ingleses, libro que Martí alaba en la crónica sobre el filósofo. Decía Emerson: 
When the war is over, the mask falls from the affectionate and domestic tastes, which make them women in kindness. This union of qualities is fabled in their national legend of "Beauty and the Beast," or, long before, in the Greek legend of Hermaphrodite. The two sexes are co-present in the English mind. [...] The English delight in the antagonism which combines in one person the extremes of courage and tenderness. [énfasis nuestro] (419)

En este fragmento del libro de Emerson aparece la metamorfosis del guerrero en hombre doméstico, donde éste adquiere características hemafroditas. Si éste fuera el caso, en el poema de Martí no sería la seducción de la mujer lo que provoca el afeminamiento del héroe, más bien ésta parecería ser un rasgo característico de la vida doméstica, de los cuidados del niño, de la paz del hogar, una condición deseada e intrínseca a los hombres de "genio superior". Sin duda, tanto Whitman como Emerson eran para Martí espíritus superiores, y si esa era la aspiración del primero, Martí también describe al segundo como una mezcla de "ternura angelical” y “cólera sagrada” (XIII, 17) semejante al Aquiles de Homero. En Ismaelillo, el guerrero que ha dejado sus armas por un momento se rinde a los reclamos del hijo y a los cuidados del hogar.

La unión de estas características opuestas resulta aún más subversiva si lo analizamos sobre el trasfondo de la tipología darwinista de la evolución. Como afirma George Cotkin, Darwin sugería en The Descent of Man (1871) que en la evolución del hombre y la mujer habían surgido especializaciones diferentes. El primero, a través de la selección natural había desarrollado las capacidades del coraje, la fuerza, la imaginación, y la inteligencia, mientras que la mujer las de la percepción, la capacidad intuitiva y la ternura maternal (76). Pues bien, en el poema "Príncipe enano”, de Ismaelillo, Martí expresa su temor por el hijo de una forma femenina, de ternura maternal:

$$
\begin{aligned}
& \text { Si se me queja,-- } \\
& \text { Cual de mujer, mi rostro } \\
& \text { Nieve se trueca. } \quad \text { (I, 19) }
\end{aligned}
$$

Al compararse con una mujer, Martí pone el énfasis en sus cualidades maternales y va en busca de la unidad que es igualmente perceptible en "Musa traviesa”, donde al ascender el hablante poético a la naturaleza-mujer, une lo femenino a la masculino, la mente del poeta con el alma de la naturaleza, el gran todo. Así se unen las dos energías que en el inicio se dividieron, que como en la crónica sobre Whitman, el poeta prevé se unirán en el futuro. En esencia, la misma filosofía aparece en su convicción de que la palabra "universo" sintetiza el concepto de lo diverso en lo uno, "lo universo, lo uni-vario, es lo vario en lo uno" (II, 164). Como apunta Mircea Eliade, la idea del andrógino es una forma arcaica de expresar el todo, la confluencia de los contrarios. Simboliza la perfección, el conocimiento de lo uno y lo otro, la síntesis de los contrarios. En los poetas modernistas expresará una aristocracia natural, el demonismo pagano y todo lo provocador que significó el siglo xix. En los poemas de Martí reaparecen de diversas formas la idea del andrógino. Con el título precisamente de “Síntesis”, escribió Martí en México un poema donde reaparece este mito. Dice el cubano: 
El alma universal dos hijos tuvo:

Cada ser en mitad viene a la tierra:

¡Así es toda la vida del humano

Buscar, siempre buscar su ser hermano! (II, 43)

Aquí Martí habla de un origen común en el cielo (mito). El hombre en el inicio, como ocurre en el mito neoplatónico, era una identidad hombre/mujer y después de la caída, después que “viene a la tierra”, cae en la división. Cada uno es uno solo, de ahí que busque esa otra "mitad". Y es que la idea del andrógino reaparece con tal frecuencia en Martí que por momentos parece ser una verdadera obsesión. En una de sus crónicas del año 1887 en que describe la Estatua de la libertad en Nueva York ésta adquiere en un momento características igualmente hermafroditas. El cubano la compara con el "Jupiter de Fidias, todo de oro y marfil, hijo del tiempo en que aún eran mujeres los hombres” (XI, 109). Martí se está refiriendo al Zeus del Olimpo al que también Moreau dedicó un cuadro. Como fue el caso de otros modernistas fin de siècle el griego es el ideal estético de belleza, cuya representación es necesaria para legitimar las nuevas construcciones de la modernidad. De esta forma Martí inscribe la simbología de lo arcaico en lo moderno, reconstruye la figura monolítica de la estatua con las citas de la cultura y de esa forma funde lo eterno y lo mítico con lo nuevo y transitorio. La misma representación ambigua aparece en su descripción de las muchachas de su novela Lucía Jerez, quienes “estaban [...] en aquella pura edad en que los caracteres todavía no se definen” (XVIII, 195). Las características físicas de las tres amigas sólo son comparables con las del personaje enigmático y misterioso de Goethe, el/ la joven Mignon, cuyo busto tienen en la mejor habitación de la casa rodeado de libros y cuadros que hablan sobre ella. Se sabe que tanto la novela de Goethe como la de Balzac, Sarrazine, sirvieron a un sin número de narraciones de este tipo en el siglo XIX, entre las cuales no deja de estar la cubana “Mozart ensayando su requiem” (1881) de Tristán de Jesús Medina.

Pero donde mejor se aprecia tal vez esta ambigüedad genérica en las figuras de Martí es en las descripciones que hace del poeta, de rostro pálido, y asociado a los ángeles celestiales. Es el "pálido ángel” que "Ilora” y abre sus alas en el pecho del héroe en “Amor errante" (I, 36). A las características hermafroditas de estos seres celestiales se refería cuando comentaba la teoría de Swedenborg, y decía que los misionarios suecos iban "describiendo, con la lengua de llamas de Swedenborg, la fusión de los sexos en los ángeles" (XI, 430). Recordemos que Swedenborg era el sueco que tuvo para Martí "mente oceánica" (XIII, 21). Asimismo, la representación de ángeles con rasgos andróginos data de una larga tradición tanto en la iconografía clásica, en la virreinal de la colonia o en el simbolismo de finales de siglo. No hay que decir que los cuadros de Moreau y las ilustraciones de Doré abundan en representaciones genéricas de este tipo, y que especialmente Moreau pensaba que el poeta era un ser andrógino (Litvak, 151). Y no es difícil ver entonces que en estos seres celestiales, el poeta proyecta algunas de las características deseadas de su personalidad. Acaso, las energías, que según Martí, Whitman “prevé” se han de unir en la vida futura ¿̇no serán en los ángeles?

Igualmente en su construcción de la figura del hijo como un alter ego del padre, el poeta lo llama “diablo ángel” y nuevamente lo identifica con los dos extremos sexuales. El niño 
es la unión del sol y la luna, el "buen maridaje” (I, 50) de lo masculino y lo femenino, la totalidad del Universo y del ser.

Que Martí encuentre atractiva la idea del andrógino no debe ser una sorpresa para lector alguno de la literatura romántica y decadentista. Por lo tanto, se puede concluir que en el universo creado por Martí reina un erotismo cerebral, mítico y cósmico, identificado en la figura de la mujer hermafrodita, el hombre-vegetal, y los ángeles celestiales que es consustancial a las corrientes estéticas del siglo XIx. En la búsqueda del ideal andrógino la palabra final es la esterilidad, el narcisismo, y la autosatisfacción. En "Brazos fragantes" el poeta andrógino opta por el hijo y el collar de "místicos lírios”. La decisión se volverá una apuesta por la soledad. Martí impone así un límite a la propia transgresión del cuerpo en el poema. Evita caer en el poder fatal y mentiroso del eros. Su poesía tratará de exorcizar cualquier indicio femenino y provocador en adelante.

\section{BiBLIOGRAFÍA}

Buci-Glucksmann, Christine. "Catastrophic Utopia: The Feminine as Allegory of the Modern”. The Making of the Modern Body: Sexuality and society in XIX Century. Catherine Callagher y Thomas Laqueur, eds. Berkeley: University of California. 22029.

Calderón de la Barca, Pedro. Obras completas. Vol. III. Autos sacramentales. Madrid: Aguilar, 1952.

Carpentier, Alejo. "Martí y Francia”. En torno a José Martí. Coloquio Internacional. Bordeaux: Biere, 1973. 511-34.

Cotkin, George. Reluctant Modernism. American thought and Culture 1880-1900. Nueva York: Twayne, 1992.

Díaz Quiñones, Arcadio. “Martí, las guerras del alma”. Apuntes Postmodernos 5/2 (1995): 4-13.

Eliade, Mircea. Shamanism: Archaic Techniques of Ectasy. Willard R. Trask, trad. Nueva York: Pantheon Books, 1964.

Emerson, Ralph Waldo. The Portable Emerson. Nueva York: Penguin, 1981.

Esteban, Angel. “La doble ‘otredad’ realizativa en Ismaelillo”. José Martí, el alma alerta. Granada: Comares, 1995. 117-88.

Foucault, Michel. "Prefacio a la Transgresión”. De lenguaje y literatura. Barcelona: Paidós, 1996. 123-42.

González, Aníbal. "Modernist Prose”. The Cambridge History of Latin American Literature. Tomo II. 3 vols. Roberto González Echevarría y Enrique Pupo-Walker, eds. Cambridge: Cambridge University Press, 1996. 69-113.

Lacan, Jaques. Écrits. A selection translated from the French from Alan Sheridan. Londres: Tavistock, 1977.

Litvak, Lily. Erotismo fin de siglo. Barcelona: Bosch, 1979.

Martí, José. Poesía Completa. 2 vols. Ed. Crítica de Cintio Vitier, Fina García Marruz y Emilio de Armas. La Habana: Letras Cubanas, 1985. Obras Completas. 28 vols. La Habana: Editorial Nacional de Cuba, 1963. 
Medina, Tristán de Jesús. Narraciones. Selección y prólogo de Roberto Friol. La Habana: Letras Cubanas, 1990.

Rodríguez, Aníbal. “Una interpretación psicológica de Martí”. Pensamiento y acción de José Martí. Conferencias y ensayos ofrecidos con motivo del primer centenario de su nacimiento. Santiago de Cuba: Universidad de Oriente, 1953. 381-419.

Showalter, Elaine. Sexual Anarchy: Gender and Culture at the Fin de Siècle. Nueva York: Viking, 1990. 